Please cite this article as:

Dell'Era C, Altuna N and Verganti R (2018).

Designing Radical Innovations of Meanings for Society: Envisioning New Scenarios for Smart Cities

Creativity and Innovation Management.

(DOI: 10.1111/caim.12276) 


\title{
DESIGNING RADICAL INNOVATIONS OF MEANINGS FOR SOCIETY: ENVISIONING NEW SCENARIOS FOR SMART MOBILITY
}

\begin{abstract}
Design-driven innovation literature focuses on meanings that people give to products and services. This paper investigates how new meanings can be designed and proposed to society rather than to individuals in the particular context of smart mobility. Smart mobility is characterized by a wide range of digital technologies that aim to make all mobility services within a city or territory more accessible and easy to use for citizens. At the same time, to effectively create value, the opportunities digital technologies offer must meet the needs of emerging lifestyles. In modern life, people manifest their interest in the semantic dimension by embracing solutions that are personally constructive and aligned with their cultural values. From an empirical point of view, this paper relies on two case studies that illustrate radical innovation of meanings in the smart mobility domain. Both case studies suggest a multi-level perspective: on the one hand, they address landscape pressure and the need for more sustainable solutions for future mobility; on the other hand, they propose a new understanding of transport and travel.
\end{abstract}




\section{Introduction}

Several methods and tools support companies in capturing and interpreting functional and utilitarian needs. Technological innovation has captured the most attention, particularly with respect to radical innovation (Abernathy and Clark, 1985; Tushman and Anderson, 1990; Utterback, 1994; Christensen and Bower, 1996; Christensen, 1997; Garcia and Calantone, 2002; Calantone et al., 2010). A rich body of literature addresses technology forecasting (Drucker, 1970; Twiss, 1992), technology foresight (Grupp and Linstone, 1999; Martin, 1995), and technology road mapping (Barker and Smith, 1995; Bray and Garcia, 1997; Groenveld, 1997; Petrick, 2004; Phall et al., 2004), providing several methods and tools to predict the evolution of technologies and their potential. Conversely, several scholars underline the potential of user-centred approaches (e.g., Chayutsahakij and Poggenpohl, 2002; Dell'Era and Landoni, 2014). The competitive results achieved by design firms such as IDEO (Kelley, 2001) and Continuum (Lojacono and Zaccai, 2004) clearly show the relevant role users can play in stimulating innovations. Firms can leverage unique insights deriving from explicit user needs and behaviours. These innovations bring a firm closer to existing behaviours, allowing understanding how people currently give meanings to things (Verganti and Dell'Era, 2014). Usercentred innovation often concerns better ideas to solve established problems; put differently, a new how, a new way to address the challenges considered relevant. A novel solution may provide incremental or even radical improvements, but always in the same direction: they are "more of the same" innovations. Design-driven innovation is about a novel purpose that redefines the problems worth addressing; not only a new how, but especially a new why. In other words, using design as a driver of innovation means moving from the "what" of a product (its features) to the "why", innovating the reason, the purpose, why people buy and use things. This inherently implies acting not only on the utilitarian dimension of use, but also on the emotional/symbolic meaning (Verganti, 2009, 2017; Verganti and Dell'Era, 2014).

Models and frameworks that support the interpretation of emerging lifestyles and new socio-cultural paradigms constitute a research area that requires further contributions. Understanding the hidden dynamics of socio-cultural models enables proposing radically new meanings (Verganti, 2009). While customers' contributions can be particularly significant in the case of functional innovation, users hardly anticipate 
radical changes in product meanings. The socio-cultural context in which they are currently immersed influences their perceptions and reflections to the point that they tend to propose interpretations that are not particularly distant from what is occurring today (Csikszentmihalyi and Rochberg-Halton, 1981; Cooper and Press, 1995; Margolin and Buchanan, 1995; Verganti and Dell'Era, 2014). According to Verganti (2010), "Only forward-looking executives, designers, and, of course, policy makers may introduce sustainable innovations into the economic picture. They need to step back from current dominant needs and behaviours and envision new scenarios. They need to propose new unsolicited products and services that are both attractive, sustainable, and profitable. It is only within the framework of a vision-centred process that users can provide precious insights".

Design-driven innovation literature focuses on meanings that people give to products and services. This paper aims to investigate how new meanings can be designed and proposed to society rather than to individuals, thereby exploring the social perspectives of radical innovations. From an empirical point of view, smart mobility is an interesting research domain for several reasons. With "smart mobility" we intend the adoption of digital technologies that make all the mobility services within a city or a territory more accessible and easy to use for citizens. Digital technologies provide incredible opportunities to citizens in terms of real-time planning, open traffic data, social customer services, etc. At the same time, to effectively create value, these opportunities must meet the needs of emerging lifestyles (Verganti, 2009; Kraus et al., 2015).

The empirical results of this research are based on two case studies concerning smart mobility within and towards a city. The Copenhagen Wheel is a new emblem for urban mobility that transforms ordinary bicycles into hybrid e-bikes using technology similar to the Kinetic Energy Recovery System. BlaBlaCar is an online platform for car sharing among interested participants. The article is structured as follows. The next section summarises the main literature on design-driven innovation. Thereafter, an overview of the research methodology used in the analysis is presented. The subsequent section describes and discusses the empirical results. The final section presents conclusions and avenues for future research. 


\section{Literature background}

When willingness to change extends beyond finding new solutions to existing problems, but aspires to developing new meanings, particular approaches and practices are required (Verganti, 2009, 2017). Design-driven innovation entails discovering and implementing a different reason, a different why for the use of a new product or service (Dell'Era and Verganti, 2007; Verganti, 2009; Dell'Era and Verganti, 2011). In other words, this type of innovation concerns a novel vision that redefines the problems worth addressing and takes innovation to a higher level - not only a new "how" but especially a new "why", proposing a new reason for why people use things (Sinek, 2011; Madsbjerg and Rasmussen, 2014; Verganti, 2017).

Specifically, each product can convey meanings, and product innovation must consider three different categories of meanings: functional, symbolic, and emotional. According to Krippendorff (1989), a major theorists of product semantics, the etymology of design goes back to the Latin root de + signare meaning "making something, distinguishing it by a sign, giving it significance, and designating its relation to other things, owners, users or goods". Several scholars in different fields, such as cultural anthropology, cognitive sciences, semiology, sociology of culture, production of culture (Hirsch, 1972; Becker, 1982; Du Gay, 1997; Hesmondhalgh, 2002; Peterson and Anand, 2004; Staber, 2008), indicate the relevant role of innovative symbols and meanings. Cultural production is the process by which cultural products (including goods, artefacts, visual and experiential objects, services, and art forms) are created, transformed, and diffused in creating a consumer culture (Lash and Urry, 1994; Kozinets, 2001, 2002; Aage and Belussi, 2008).

While meanings are not simply given, and we therefore can only attempt to understand these through market research, they can be innovated, even radically, as a result of the evolution of the socio-cultural context and the emergence of new technologies (Verganti, 2006, 2011, Dell'Era and Verganti, 2007; Dell'Era and Bellini, 2009; Dell'Era et al., 2010). Innovation can be based on new technologies, meanings, or both. These dimensions can be innovated incrementally or radically. The vertical axis of Figure 1 refers to the most widespread dimension in managing innovation, the utilitarian function, which derives from product performance and is based on technological development. The horizontal dimension indicates meaning, denoting the "why" of a product. 


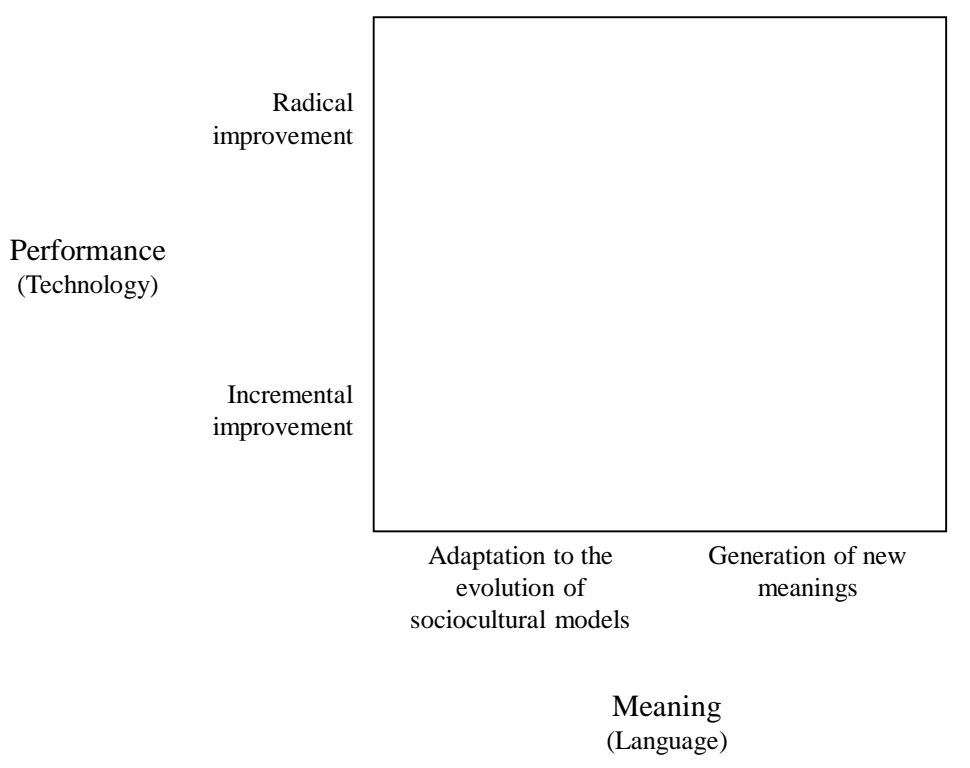

Figure 1: Performance and meaning (Verganti, 2009)

Research shows that design-driven innovation requires collaborating with external networks to expose companies to different perspectives (Brode et al., 2014; Dell'Era and Verganti; 2010; Verganti and Dell'Era, 2014). The importance of open innovation processes for value creation in radical innovation is not new (Leifer et al., 2000; McDermott and O'Connor, 2002). However, in the case of design-driven innovation, external actors play a critical role as "interpreters".

Firms developing design-driven innovations need to collaborate with different categories of interpreters to explore new scenarios. Verganti (2009) defines interpreters as "firms in other industries that target the same users, suppliers of new technologies, researchers, designers, and artists, that can provide complementary and synergistic knowledge" (see Figure 2). These can be grouped into two main categories: the world of cultural production (i.e., people whose core mission is exploring culture and meaning) and the world of technology (i.e., people who focus their efforts on exploring radical changes in technologies and drive technical innovations). To develop design-driven innovations, firms must enter into dialogue with this external network, which enables taking a step back from their own view of the industry and facilitates a more holistic 
interpretation of the surrounding sociocultural arena (Verganti, 2009; Verganti and Dell'Era, 2014).

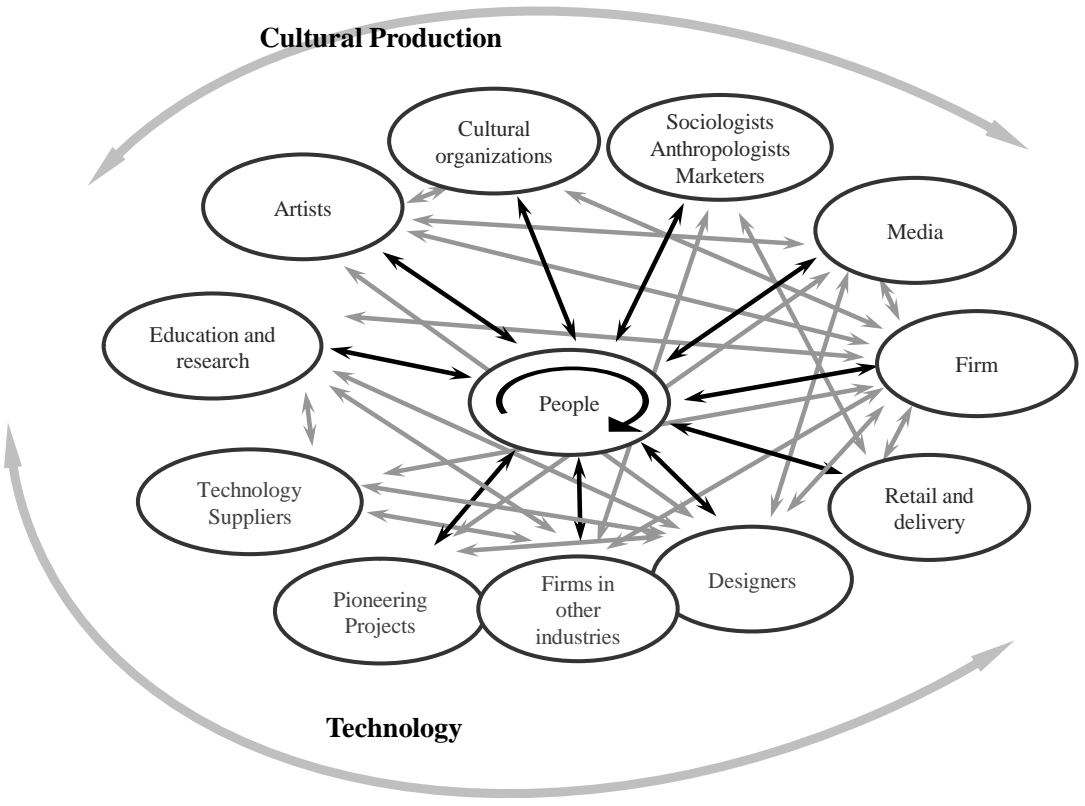

Figure 2: The interpreters in design-driven innovation (Source: Verganti, 2009)

\section{Research methodology}

As mentioned, this paper investigates how new meanings can be designed and proposed to society rather than to individuals according to design-driven innovation literature (Verganti, 2009). While prior studies investigate the effectiveness of radical innovations of product meanings proposed to individuals, the present paper aims to explore the approaches companies adopt in proposing new meanings to society.

\subsection{Empirical setting: Smart Mobility}

This paper investigates solutions proposed in the field of smart mobility for several reasons. Smart mobility is characterized by a wide range of digital technologies that aim to make all the mobility services within a city or territory more accessible and easy to use for citizens. Digital technologies provide incredible opportunities in terms of realtime planning, open traffic data, social customer services, etc. This phenomenon is the result of unprecedented urbanisation and the unparalleled and increasing wealth of 
information. More specifically, transportation is an intriguing domain as it constitutes the circulatory system of our economy and has an important societal function (Geels, 2004). Globalisation, population growth, and unchecked urbanisation are expected to lead to the collapse of existing transportation systems. The need for continuous interactions between a transportation mode and its population is thus evident.

At the same time, to effectively create value, the opportunities that digital technologies provide must meet the needs of emerging lifestyles. In modern life, people manifest their interest in the semantic dimension by embracing solutions that are personally constructive and aligned with their cultural values. For this reason, smart mobility is an appropriate empirical setting to analyse the development of radical innovations of meanings for society. Several initiatives that aim to improve mobility are intrinsically "systemic" and require the contribution of several actors who interact through a complex set of relationships. Moreover, these initiatives frequently focus on the social needs of large communities rather than on those of a small set of individuals.

\subsection{Illustrative Case Studies}

We chose the Copenhagen Wheel and BlaBlaCar as our illustrative cases as relevant examples of radical innovation of meanings for society (Verganti, 2009 and 2017). They do not only provide innovative services from a functional point of view, but propose new interpretations of the role of bicycles and travel. The Copenhagen Wheel was developed by MIT's SENSEable City Lab for the City of Copenhagen and consists of a wheel that can turn an ordinary bike into an electric hybrid with regeneration and real-time environmental sensing capabilities. Adopting a technology similar to KERS (Kinetic Energy Recovery System), the Copenhagen Wheel is able to capture the energy dissipated while cycling and braking, storing it to boost subsequent locomotion. It is also able to collect data on pollution levels, traffic congestion, and road conditions in real time. The number of electric bicycles around the world is significantly growing (Cherry, 2007) for several reasons, such as rising oil prices or distance issues. However, the number of people who cycle to work has remained constant over the last fifteen years in countries such as Denmark, where cycle policies and the cycling infrastructure are already excellent, indicating that other problems remain in fostering the new culture. BlaBlaCar is a long-distance ridesharing community. It was conceived in December 2003 
by Frédéric Mazzella and then founded in 2006. BlaBlaCar connects drivers and passengers willing to travel together between cities and share the cost of the journey. BlaBlaCar has received over 50 prizes and honours since its creation, and now has over 600 employees and more than 35 million members across 22 countries.

While our study is not inductive, it aims to exploit the insights from both case studies to illustrate the particularities of radical innovation of meanings for society (Verganti, 2009 and 2017). This approach enables close correspondence between the theory and the data (Glaser and Strauss, 1967; Siggelkow, 2007). The paper relies on multiple sources of information in developing the illustrative case studies. Specifically, data were collected from company websites and other secondary sources, such as videos, business reports and presentations, press releases and magazine articles between 2012 and 2017 (see Appendix 1 reporting the list of the main data sources).

We analysed the data using an iterative process, moving back and forth between the data and the theory. More specifically, we analysed the documents using an iterative process consisting of three main phases: reading, coding, and interpreting (Strauss and Corbin, 1998). To ensure the integrity of our data, we triangulated the multiple sources, independently read the data and information, and discussed our interpretations in faceto-face meetings to resolve potential misunderstandings and divergent views. Each case study was conducted to identify and understand the key issues facing each project. More specifically the case studies focus on the interpreters belonging to the domains identified by Verganti (2009):

- Technology Network: interpreters who due to their technical innovations have developed products or services that generated change, affecting the way we interact, and proposing new meanings. This group is linked more to the production side of the aforementioned socio-technical systems;

- Cultural Production: interpreters committed not only to technological research but also to research on the production of social meaning, including those whose research objectives and thinking embrace the exploration of cultural and social dynamics to unveil possible future scenarios and meanings. This view is needed to understand the user side of an innovation system and must be included to identify how radical innovations should be managed. 
In addition, we mapped the collaborators' contributions focusing mainly on the core team driving the project to enable assessing not only their competencies, but also their individual contributions to the overall project.

\section{Empirical results and discussion}

In this section, we report the main findings from the two smart mobility case studies (Copenhagen Wheel and BlaBlaCar). The first case concerns the concept of electrically powered mobility, while the second refers to a platform that acts as an intermediary to connect people and share trips.

\subsection{Copenhagen Wheel}

The Copenhagen Wheel addresses mobility challenges not through incremental improvements to e-bike technology, but through reinventing the meaning of the wheel. To do so, the team began working with the municipality of Copenhagen in 2008 to explore how technology could improve the cycling experience, and how distance, topography, infrastructure, and safety (the four main obstacles to getting people on bikes) could be overcome. Their holistic approach enabled them to propose solutions that were not closed to the technical brief but were also open to other areas of expertise, taking advantage of the potential that digital networking of people, objects, and cities offers using real-time information (Outram et al., 2010). Proposing a new meaning of the bike concept and fostering a culture in which technological intelligence is a component of daily objects led to creating a smart and supportive infrastructure centred on citizens. The Copenhagen Wheel is not just a bicycle or a green mode of urban commuting, but also an opportunity for citizens to participate in maintaining public resources and influence change in their towns and cities through electric mobility. The technology allowed developing a new concept that changes how citizens envision a bicycle, from a bicycle as a means of transport to a bicycle as a city sensor; the semantic shift is evident (see Figure 3 and Appendix 2). 


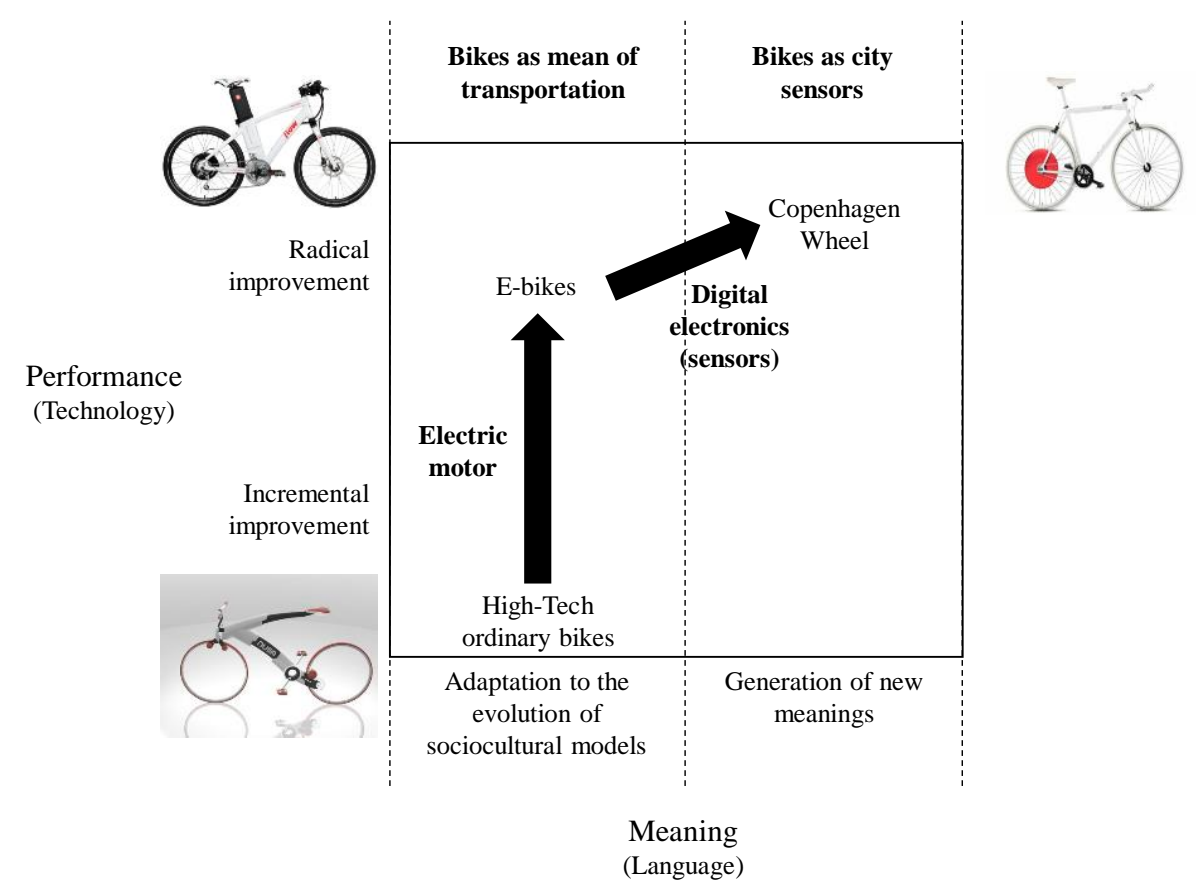

Figure 3: Copenhagen Wheel - innovation of performance and meaning

The Copenhagen Wheel debuted at the COP15 United Nations Climate Conference in 2009 and went on to win several design awards, including the James Dyson Award. The Wheel was developed at the MIT SENSEable City Lab (initially in collaboration with the Smart Cities Group at MIT for the development of the first prototype) and presales were expected to start in December 2013. Once on the market, the intention was to disrupt the market for e-bikes by offering a new mobility solution in cities while simultaneously providing an unparalleled biking experience.

The Copenhagen Wheel allows to capture the energy dissipated while cycling and braking and save it for when the user needs a bit of a boost. It also maps pollution levels, traffic congestion, and road conditions in real-time. Controlled through the smartphone, the Copenhagen Wheel aspires to become a natural extension of the everyday life. Through the smartphone the user can lock and unlock the bike, change gears and select how much the motor should assist the user. During the cycling experience, the sensing unit built on the wheel captures the effort level developed by the user and the information about the surroundings, including road conditions, carbon monoxide, NOx, noise, ambient temperature and relative humidity. Collected data can be used in order to plan healthier bike routes, achieve specific goals or meet up with friends on the go. 
The user can also anonymously share the data with other citizens contributing to a finegrained database of environmental information from which all citizens can benefit. In other words the Copenhagen Wheel is not simply an innovative vehicle supporting transportation, but allows citizens to make a bigger contribution through their daily commute. Sharing the data collected by the sensing wheel, the city can gain access to a new scale of fine-grained environmental information. This type of crowd sourcing can influence how the city allocates its resources, how it responds to environmental conditions in real-time or how it structures and implements environmental and transportation policies. As noted by Assaf Biderman, Associate Director of the MIT SENSEable City Lab,

"As bikers collect and share air quality data, cycling becomes more than a clean mode of transport. It opens yet another door for citizens to participate in governance and in the maintenance of public resources."

Clearly, rich dialogue among actors from different backgrounds was needed to successfully tap into the knowledge of product meanings and languages, and thus to make design-driven innovation happen. In the case of the Copenhagen Wheel, the challenge was undertaken by a multidisciplinary team that consisted of architects and urban planners, mechanical and electrical engineers, computer scientists, an interaction designer, and a physicist. The Copenhagen Wheel is a mix of inspirations from very different fields, such as Formula One racing, gaming, urban planning and design, social networking, sensor systems, real-time data collection, and web development. Above all, technical knowledge is the distinguishing feature of this case through the thinking inspired by project leader Christine Outram, who disregarded incremental technical improvements in favour of a leap-frog solution that improved the cycling experience with the potential of fostering the cycling culture in cities. Worth noting is the wide variety of technology researchers surrounding Outram throughout the project, from software engineers to renewable energy experts to computational designers. This team contributed to providing the knowledge and technological expertise to nurture the global technology and design discourse (see Appendix 3). According to Christine Outram, Copenhagen Wheel Project Leader, 
"One of the applications we developed for the city is a Green Mile program, which is similar to a frequent flyer program, but good for the environment. [...] It opens the door for individuals to participate in plans to reduce emissions, such as carbon cap and trade, which have so far been offered mostly to large organizations."

Awarded with the Red Dot 2014, the Copenhagen Wheel has been reviewed in over 2,000 media publications, including BBC, Wired, The Guardian and the New York Times demonstrating the innovativeness and the relevance of the product. In 2017 Time named the Copenhagen Wheel one of the Best Pieces of Tech in 2017.

\subsection{BlaBlaCar}

BlaBlaCar is a car-sharing platform operating in Europe that connects drivers who have empty seats with passengers looking for a ride. By sharing long-distance rides, the community contributes to the improvement of road transport efficiency, saving money on travel while reducing the environmental impact. Most BlaBlaCar journeys are long distance (more than $150 \mathrm{~km}$ ), as these are both more expensive and often planned in advance. BlaBlaCar uses a simple, three-step mechanism: drivers planning a longdistance car journey offer their ride online, specifying itinerary and price; passengers interested in the trip contact the driver via BlaBlaCar internal messages or phone; the driver and passenger then travel together and the passenger pays the driver a contribution to help offset his/her costs.

The uniqueness of the system is its social side and explained by the company's name: BlaBlaCar (when members sign on and create their profiles, they indicate their level of in-car chattiness from Bla to BlaBla to BlaBlaBla). Making travel more social is one of the company's main objectives as well as proposing a new understanding of travel, moving from a comfortable and self-focused activity to an affordable and social one. To execute its business plan, the company took advantage of the Internet and created an online platform, which in 2007 was reinforced with a mobile application (see Appendix 4 for further details). Figure 4 depicts this innovation based on a change in meaning compared to existing car-sharing platforms where the concept of travel remains unchanged. 


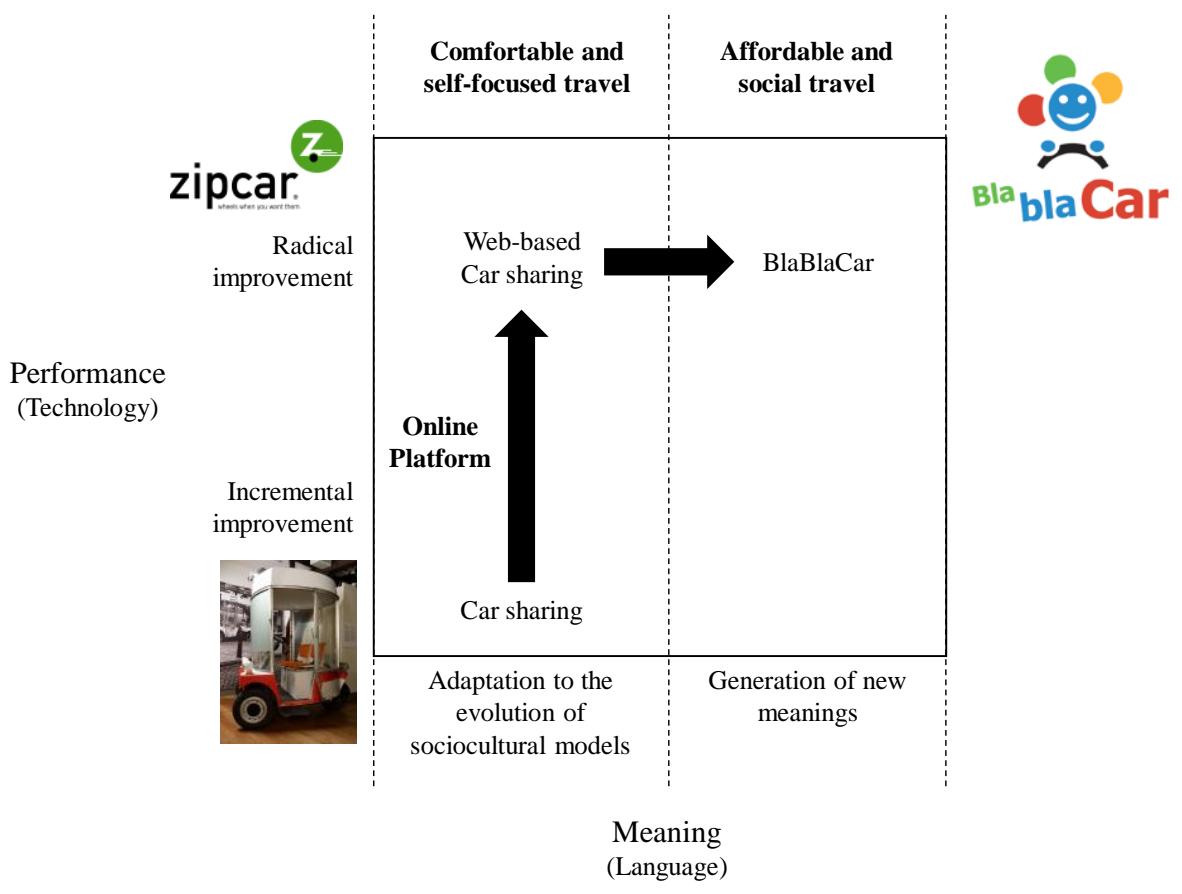

Figure 4: BlaBlaCar - innovation of meaning

Twelve years after its founding in 2006, the platform is now available in 22 countries and has more than 40 million members. On average, 4 million people share rides every month through the company's website and mobile apps. The visionary behind the BlaBlaCar idea was Frédéric Mazzella, a physicist who had previously worked as a researcher and earned an MBA just before founding the company. Mazzella was inspired by a situation in which he found himself with no way to travel home for Christmas. Along with two other people who provided technical support for the implementation of the idea, Mazzella built the community that sustains the platform (see Appendix 5).

According to BlaBlaCar vision, carpooling creates a unique space, enabling exchanges between people who might have never met otherwise, but who come together to share a ride; the mission statement proposed by BlaBlaCar is "We imagine a fairer, more open world of travel. Where people are better connected and independent." BlaBlaCar has recently conducted the largest study on the social impacts of carpooling: "Bringing People Together" ${ }^{11}$. In collaboration with the consultancy firm Le Bipe, the study is based

\footnotetext{
${ }^{1}$ The study was conducted by French research consultancy Le BIPE in fall 2016. A total of 4,733 BlaBlaCar members were surveyed in 9 countries (France, Germany, Hungary, Italy, Poland, Russia, Spain, Ukraine and UK).
} 
on almost five thousands answers to a survey investigating social interactions enabled by BlaBlaCar. According to this study, carpooling is unlocking convenient and affordable transport resulting in $45 \%$ of members declaring that they travel more, organise more holidays and week-end trips since they started carpooling. $80 \%$ of BlaBlaCar members carpool to see their friends and family. Among them, $60 \%$ declare they see their loved ones more thanks to BlaBlaCar. Among the members who have declared that the profiles of people they met on BlaBlaCar were more diverse than their social circles, close to half of respondents (47\%) recognise that carpooling has made them more open to other cultures and opinions. As noticed by Frederic Mazzella, Founder of BlaBlaCar,

"At first glance the BlaBlaCar's contribution to society is mainly economic and environmental (through the optimized use of idle car capacity). But it's also magical. We're able to build better interactions between people because we are building a network of trust in which everybody knows the people they'll be riding with. You have profiles, you have pictures, biographies, and preferences, and you have the ratings of the members. We are building an environment for trust. And this is actually much better for humanity, because you're able to trust people you've never met thanks to digital trust tools, opening up great opportunities for peer-to-peer collaboration. Our members share a long-distance ride, and enriching social experiences too."

\section{Discussion and Conclusions}

This paper investigates how new meanings can be designed and proposed to society rather than to individuals. The paper provides two main theoretical contributions: (i) the role of meanings in influencing societal behaviours and lifestyles and (ii) the contribution of technologies in enabling radical innovation of meaning for society.

More specifically the paper focuses on those meanings able to influence and stimulate behaviours among individuals; while functional and emotional meanings address personal interpretations (Pierce, 1935; Gotzsch, 2000; Verganti, 2003), social or symbolic meanings affect how people interact and relate one each other. Both case studies provide intriguing insights on the potentialities of radically new meanings in changing societal behaviours and lifestyles. These case studies suggest a multi-level 
perspective. On the one hand, they address landscape pressure and more specifically both case studies show a growing need for more sustainable mobility solutions. For example, according to Carlo Ratti, Director of the MIT SENSEable City Lab,

"The Copenhagen Wheel is part of a more general trend of inserting intelligence into our everyday objects to create a smart, supporting infrastructure around ourselves."

BlaBlaCar is part of a powerful movement changing our everyday lives for the better: sharing economy. As noticed by Frederic Mazzella, Founder of BlaBlaCar,

"Over the past few years, BlaBlaCar has offered an alternative vision, in phase with the emergence of the connected sharing economy. What has perhaps been most surprising to us is how fast things can change when others catch on to your dream. With 2 million travellers a month, the multiplier effect of a growing viral community is striking."

On the other hand, they propose new understandings of bikes or travel that originally interpret and enrich the overall landscape pressure that is looking for more sustainable solutions. Bikes as city sensors in the case of the Copenhagen Wheel and affordable and social travel in the case of BlaBlaCar differentiate both Copenhagen Wheel and BlaBlaCar from other sustainable mobility solutions. They enrich the must-have attribute about sustainability, whit more advanced delighters such as the possibility to contribute to the wellbeing of the city (in the case of Copenhagen Wheel) and get in touch with new friends (in the case of BlaBlaCar) (Kano et al., 1984).

Interestingly, the two case studies highlight the different roles the technologies played in enabling the radical innovation of meanings for society: although the meaning bikes as city sensors in the case of Copenhagen Wheel was enabled by a set of new sensors, the meaning affordable and social travel in the case of BlaBlaCar was proposed using the same technology adopted by competitors, such as web-based services (see Figure 5). 


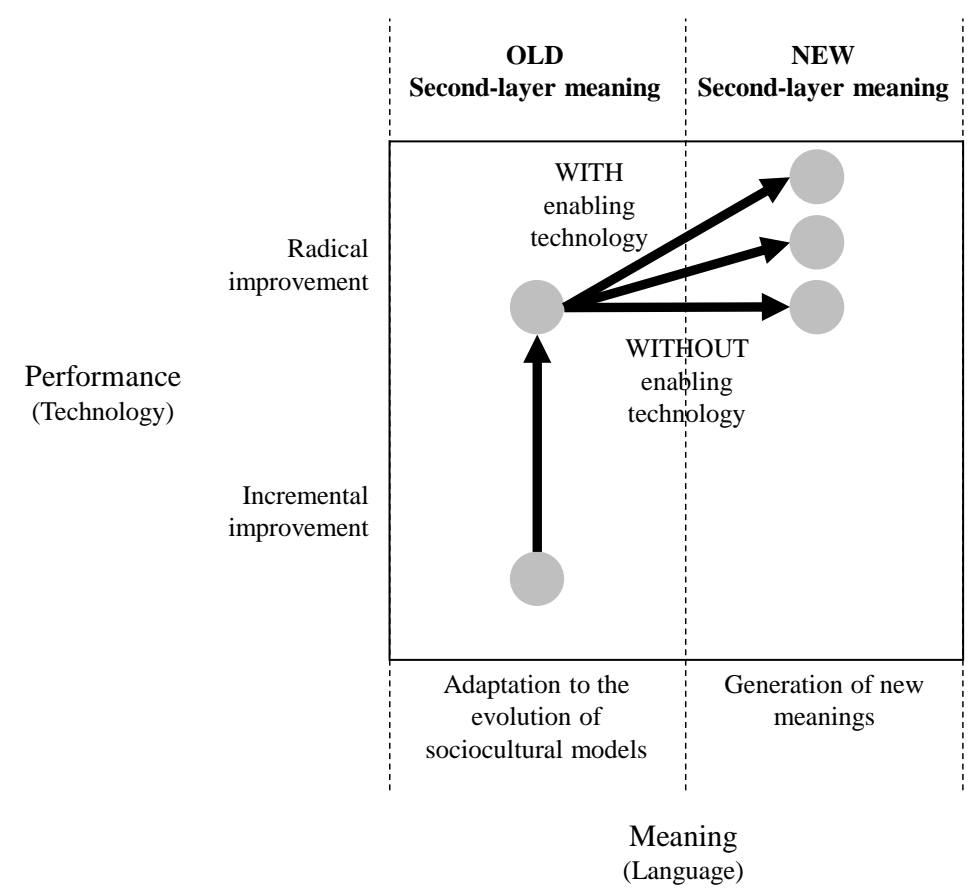

Figure 5: The role of technologies in enabling radical innovation of meanings for society

Moreover, with respect to the managerial profiles needed for such innovation, the empirical results show the existence of at least one team member with cultural expertise. In Verganti's (2009) design discourse, the need for people who understand production and show interest in investigating social meaning is a necessary but insufficient condition to propose new meanings and radical innovation. In both case studies, we find at least one individual in the project team who embodies this particular vision, even if originally identifying with the world of technology. These visionary individuals act as technological gatekeepers of cultural production. As defined by Boer and During (2001), the gatekeeper "collects and channels information about important changes in the internal and external environment". To some extent, this profile shows similarities also with the "technology-related relationship promoter" and the "market-related relationship promoter" of Gemünden et al. (2007). At the same time, the ability to "sense" and scout the emerging phenomena in the cultural production area requires particular skills, competences, and attitudes. This is not only a matter of knowing the market, but also interpreting lifestyle trends and changes in consumer behaviours (see Figure 6). In other words the concept of "technological gatekeepers of cultural production" can represent an expansion to the definition already provided by Boer and 
During (2001) and Gemünden et al. (2007) because it specifically refers to a role able to bridge cultural production and technologies.

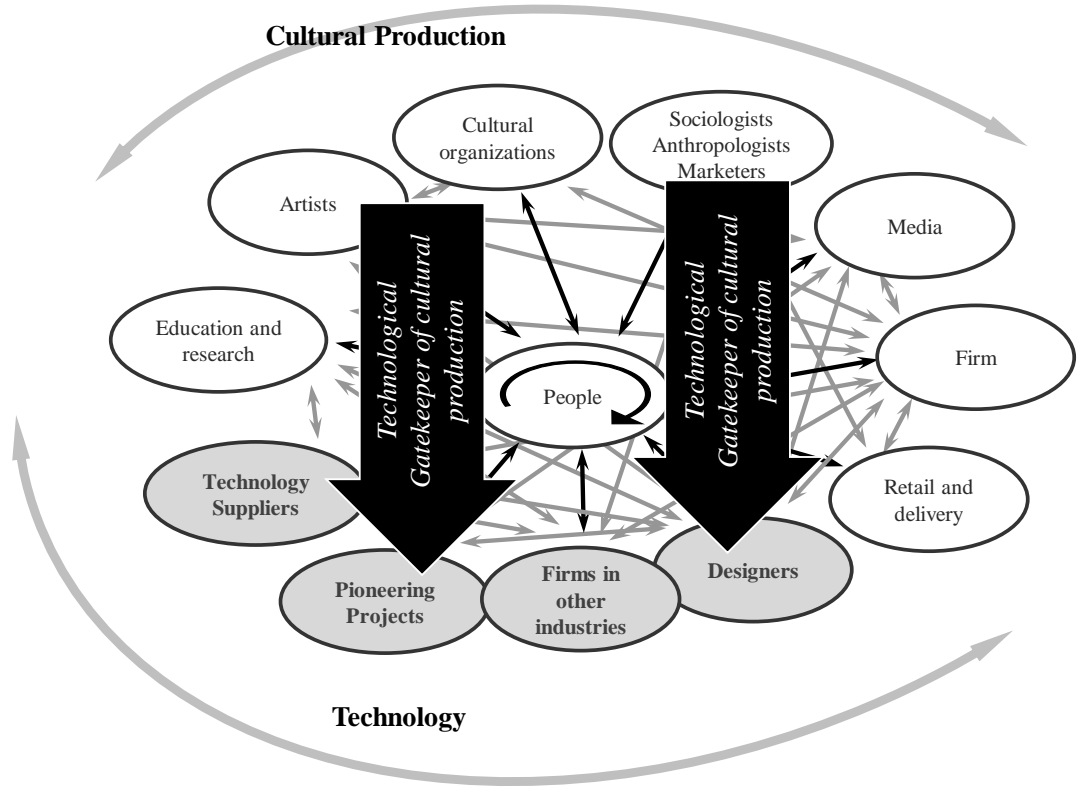

Figure 6: Technological gatekeeper of cultural production (adapted from Verganti, 2009)

In the case of the Copenhagen Wheel, project leader Christine Outram played the role of technological gatekeeper of cultural production. Outram holds an MIT Master's Degree in architectural studies (architecture and urbanism), with a special focus on distributed technologies and cities. As the founder and director of the City Innovation Group (a global think tank of researchers and entrepreneurs), she led the project during its first phase, instilling her insights and thoughts on how to disrupt general thinking to radically change the cycling culture in cities. Her expertise and management created a new concept of the bicycle, shifting from a bicycle as a means of transport to a bicycle as a city sensor with a creative strategy and design, community mobilisation and initiatives using 'big data' to create smarter, more sustainable cities and new business ecosystems. This new concept of a bicycle would not have been possible without Outram's contribution. In the case of BlaBlaCar, the visionary's technological background was stronger than in the other case. Nonetheless, the approach Frédéric Mazzella followed is close to that of a technological gatekeeper, as he was inspired by a social circumstance where he found himself with no transport to visit his family for the 
symbolic event of Christmas, but found a solution by applying his technological knowledge. Moreover, the insights on performance from other case studies (i.e., Xbox and PlayStation 3 for the gaming industry) illustrate that it is possible to succeed by acting only on the technological dimension, but that future perspectives are subsequently limited due to the rapid speed at which technology evolves, and a substitution may occur that transforms a formerly innovative project into an oldfashioned one (Verganti, 2009). In contrast, the idea of combining the functional and semantic dimensions strengthens competitive advances by opening new paths to a promising future (Buganza et al., 2015; Dell'Era et al., 2017; Trabucchi et al., 2017).

As with all research, this work has limitations as well as opportunities for further exploration. In particular, the study has two limitations. First, the extent of the sample, or how well the sample represents what is stated, is admittedly limited. The second limitation lies in the difficulty of defining an array model to measure performance for a clearer comparison. The lack of recent projects launched or in development made it impossible to gather all the data needed to define performance. In the next phase of the research, we intend to estimate all the variables more precisely that influence the contribution of technologies to the radical innovation of meaning, and thus the added

value of technology epiphanies in radical socio-technical innovations. In addition to the discussed caveats, from a research evolution perspective, different paths are possible for further exploration. The most obvious would be to extend the sample within the transport industry to obtain more rigorous and accurate empirical results. It would also be interesting from a research perspective to analyse other related societal matters, such as education or urban farming.

\section{References}

- Aage, T. and Belussi, F. (2008). From fashion to design: creative networks in industrial districts. Industry and Innovation, Vol. 15, pp. 475-491.

- Abernathy, W. and Clark, K. (1985). Innovation: mapping the winds of creative destruction. Research Policy, Vol. 14, pp. 3-22.

- Barker, D. and Smith, D.J.H. (1995). Technology foresight using roadmaps. Long Range Planning, Vol. 28, No. 2, pp. 21-28. 
- Becker, H.S. (1982). Art worlds. Berkeley, CA, University of California Press.

- Bray, O.H. and Garcia, M.L. (1997). Fundamentals of technology roadmapping. Sandia National Laboratories, Albuquerque, NM.

- Boer, H., and During, W. E. (2001). Innovation, what innovation? A comparison between product, process and organisational innovation. International Journal of Technology Management, 22(1-3), 83-107.

- Brode L, Dell'Era C and Verganti R (2014). The contributions of interpreters to the development of radical innovations of meanings: the role of "pioneering projects" in the sustainable buildings industry. R\&D Management, Vol. 44, No. 1, Pp. 1-17.

- Buganza, T., Dell'Era, C., Pellizzoni, E., Trabucchi, D. and Verganti, R. (2015). Unveiling the Potentialities Provided by New Technologies: A Process to Pursue Technology Epiphanies in the Smartphone App Industry. Creativity and Innovation Management, Vol. 24, No. 3, pp. 391-414.

- Calantone, R.J., Harmancioglu, N. and Dröge, C. (2010). Inconclusive innovation "returns": a meta-analysis of research on innovation in new product development. Journal of Product Innovation Management, Vol. 27, pp. 1065-1081.

- Chayutsahakij, P. and Poggenpohl, S. (2002). User-centered innovation: the interplay between user-research and design innovation. Proceedings of The European Academy of Management 2nd Annual Conference on Innovative Research in Management, EURAM, Stockholm, Sweden.

- Cherry, C. (2007). Electric bike use in china and their impacts on the environment, safety, mobility and accessibility. Institute of Transportation Studies, University of California.

- Christensen, C.M. (1997). The innovator's dilemma. When new technologies cause great firms to fail. Boston, MA: Harvard Business School Press.

- Christensen, C. and Bower, J. (1996). Customer power, strategic investment, and the failure of leading firms. Strategic Management Journal, Vol. 17, pp. 197-218.

- Cooper, R. and Press, M. (1995). The design agenda. John Wiley and Sons, Chichester UK.

- Csikszentmihalyi, M. and Rochberg-Halton, E. (1981). The meaning of things: domestic symbols and the self, Cambridge: Cambridge University Press.

- Dell'Era, C., Altuna, N., Magistretti, S. and Verganti, R. (2017). Discovering quiescent meanings in technologies: exploring the design management practices that support the development of Technology Epiphanies. Technology Analysis \& Strategic Management, Vol. 29, No.2, pp. 149-166. 
- Dell'Era, C. and Bellini, E. (2009). How can product semantics be embedded in product technologies? The case of the Italian wine industry. International Journal of Innovation Management, Vol. 13, No. 3, pp. 411-439.

- Dell'Era, C. and Landoni, P. (2014). Living lab: a methodology between user-centred design and participatory design. Creativity and Innovation Management, Vol. 23, No. 2, pp. 137154.

- Dell'Era, C., Marchesi, A. and Verganti, R. (2010). Mastering technologies in design-driven innovation. How two Italian companies made design a central part of their innovation process. Research Technology Management, Vol. 53, No. 2, pp. 12-23.

- Dell'Era, C. and Verganti, R. (2007). Strategies of innovation and imitation of product languages. Journal of Product Innovation Management, Vol. 24, pp. 580-599.

- Dell'Era C and Verganti R (2010). Collaborative Strategies in Design-intensive Industries: Knowledge Diversity and Innovation. Long Range Planning, Vol. 43, Pp. 123-141.

- Dell'Era C and Verganti R (2011). Diffusion Processes of Product Meanings in DesignIntensive Industries: Determinants and Dynamics. Journal of Product Innovation Management, Vol. 28, Pp. 881-895.

- Drucker, P.F. (1970). Technology, management and society. Heinemann, 1970.

- Du Gay, P. (Ed.) (1997). Production of culture: cultures of production. London: Sage.

- Garcia, R. and Calantone, R. (2002). A critical look at technological innovation typology and innovativeness terminology: a literature review. Journal of Product Innovation Management, Vol. 19, pp. 110-132.

- Gemünden, H.G., Salomo, S. and Holzle, K. (2007). Role models for radical innovations in times of open innovation. Creativity and Innovation Management, Vol. 16, No. 4, pp. 408421.

- Glaser, B. and Strauss, A. (1967). The discovery of grounded theory: strategies in qualitative research. London: Wiedenfeld and Nicholson.

- Gotzsch J (2000). Beautiful and meaningful products. Design plus research, Proceedings of the Politecnico di Milano Conference, May 18-20.

- Groenveld, P. (1997). Roadmapping integrates business and technology. Research Technology Management. Vol. 40, No. 5, pp. 48-55.

- Grupp, H. and Linstone, H.A. (1999). Foresight Activities around the globe: resurrection and new paradigms. Technological Forecasting and Social Change, Vol. 60, No. 1, pp. 85-94.

- Hesmondhalgh, D. (2002). The cultural industries. London: Sage. 
- Hirsch, P. (1972). Processing fads and fashions: an organization-set analysis of cultural industry systems. American Journal of Sociology, Vol. 77, pp. 639-659.

- Kano, N., Seraku, N., Takahashi, F. and Tsuji, S. (1984). Attractive quality and must-be quality. The Journal of the Japanese Society for Quality Control, Vol. 14, No. 2, pp. 39-48.

- Kelley, T. (2001). The art of innovation. New York: Currency.

- Kemp, R., Schot, J. and Hoogma, R. (1998). Regime shifts to sustainability through processes of niche formation: the approach of strategic niche management. Technology Analysis \& Strategic Management, Vol. 10, No. 2, pp. 175-195.

- Kozinets, R.V. (2001). Utopian experience: articulating the meanings of star trek's culture of consumption. Journal of Consumer Research, Vol. 28, pp. 67-88.

- Kozinets, R.V. (2002). Can consumers escape the market? Emancipatory illuminations from burning man. Journal of Consumer Research, Vol. 29, pp. 20-38.

- Kraus, S., Richter, C., Papagiannidis, S. and Durst, S. (2015). Innovating and exploiting entrepreneurial opportunities in smart cities: evidence from Germany. Creativity and Innovation Management. Vol. 24, No. 4, pp. 601-616.

- Krippendorff, K. (1989). On the essential contexts of artifacts or on the proposition that design is making sense (of things). Design Issues, Vol. 5, pp. 9-38.

- Lash, S. and Urry, J. (1994). Economies of sign and space. London: Sage.

- Leifer, R., McDermott, C., Peters, L., Rice, M. and Veryzer, R. (2000). Radical Innovation: How Mature Companies Can Outsmart Upstarts. Harvard Business School Press.

- Lojacono, G. and Zaccai, G. (2004). The evolution of the design-inspired enterprise. Sloan Management Review, Spring, pp. 75-79.

- Madsberg, C., Rasmussen, M.B. (2014). The Moment of Clarity: Using the Human Sciences to Solve your Toughest Business Problems. Harvard Business Review Press.

- Margolin, V. and Buchanan, R. (eds) (1995). The idea of design: a design issues reader. Cambridge: MIT Press.

- Martin, B.R. (1995). Foresight in science and technology. Technology Analysis and Strategic Management, Vol. 7, No.2, pp. 139-168.

- McDermott, C.M. and O'Connor, G.C. (2002). Managing radical innovation: An overview of emergent strategy issues. Journal of Product Innovation Management, 19, 424-438.

- Outram, C., Ratti, C. and Biderman, A. (2010). The Copenhagen Wheel: an innovative electric bicycle system that harnesses the power of real-time information and crowd sourcing. EVER Monaco International Exhibition and Conference on Ecologic Vehicles and Renewable Energies. 
- Peterson, R.A. and Anand, N. (2004). The production of culture perspective. Annual Review of Sociology, Vol. 30, pp. 311-334.

- Petrick, I. (2004). Technology roadmapping in review: a tool for making sustainable new product development decisions. Technological Forecasting and Social Change, Vol. 71, No. 1, pp. 81-100.

- Phall, R., Farrukh, C.J. and Probert, D.R. (2004). Technology roadmapping - a planning framework for evolution and revolution. Technological Forecasting and Social Change, Vol. 71, No. 1, pp. 5-26.

- Pierce CS (1935). Collected papers of Charles Sanders Peirce. Eds. Hartshorne C, Weiss P (Vols. 1-6) and Burks A (Vols. 7-8). Cambridge MA, Harvard University Press.

- Siggelkow, N. (2007). Persuasion with case studies. Academy of Management Journal, Vol. 50, No. 1 , pp. $20-24$.

- Sinek, S. (2011). Start with Why: How Great Leaders Inspire Everyone to Take Action. Penguin.

- Staber, U. (2008). Network Evolution in Cultural Industries. Industry and Innovation, Vol. 15, pp. 569-578.

- Strauss, A. and Corbin, J. (1998). Basics of qualitative research: techniques and procedures for developing grounded theory. Newbury Park, CA: Sage.

- Trabucchi, D., Pellizzoni, E., Buganza, T. and Verganti, R. (2017). Interplay between technology and meaning: how music majors reacted? Creativity and Innovation Management, Vol. 26, No. 4, pp. 327-338.

- Tushman, M.L. and Anderson, P. (1990). Technological discontinuities and dominant designs: a cyclic model of technological change. Administrative Science Quarterly, Vol. 35, pp. 604-633.

- Twiss, B.C. (1992). Managing technological innovation. Longman Group, IV Edition.

- Utterback, J.M. (1994). Mastering the dynamics of innovation. Boston, MA: Harvard Business Press.

- Verganti R (2003). Design as brokering of languages: The role of designers in the innovation strategy of Italian firms. Design Management Journal, Vol. 3, Pp. 34-42.

- Verganti, R. (2006). Innovating through design. Harvard Business Review, Vol. 84, No. 122, pp. $114-122$.

- Verganti, R. (2009). Design-driven innovation - changing the rules of competition by radically innovating what things mean. Boston, MA: Harvard Business Press. 
- Verganti, R. (2010). User-centered innovation is not sustainable. HBR Blog Network (http://blogs.hbr.org/cs/2010/03/user-centered_innovation_is_no.html, published March 19, 2010).

- Verganti, R. (2011). Designing breakthrough products. Harvard Business Review, October.

- Verganti, R. (2017). Overcrowded - Designing Meaningful Products in a World Awash with Ideas. MIT Press, Boston.

- Verganti, R. and Dell'Era, C. (2014). Design-driven innovation: meaning as a source of innovation. In Dodgson M, Gann D and Philips N. (2014). The Oxford Handbook of Innovation Management, Oxford University Press. 
APPENDIX 1 - MAIN DATA SOURCES

\begin{tabular}{|c|c|c|}
\hline Source & Copenhagen Wheel & BlaBlaCar \\
\hline Website & - www.superpedestrian.com & - www.blablacar.com \\
\hline Videos & $\begin{array}{l}\text { - The Copenhagen Wheel official product } \\
\text { release } \\
\text { (https://www.youtube.com/watch?v=S10G } \\
\text { MfG2NMY) } \\
\text { - Copenhagen Wheel review: twice the bike } \\
\text { with half the effort } \\
\text { (https://www.youtube.com/watch?v=yVU1B } \\
\text { McuQ-k) } \\
\text { - Carlo Ratti \& Assaf Biderman on how cities } \\
\text { communicate through digital technologies } \\
\text { (https://www.youtube.com/watch?v=ANKr9 } \\
\text { 34-DbU) } \\
\text { - Human-powered mobility for the future I } \\
\text { Carlo Ratti and Assaf Biderman } \\
\text { (https://www.youtube.com/watch?v=qpycW } \\
\text { vIFZFk) } \\
\text { - The Copenhagen Wheel: How Design and } \\
\text { Robotics Come Together to Transform Urban } \\
\text { Mobility } \\
\text { (https://www.youtube.com/watch?v=h9Aoy } \\
\text { kP4G1E) }\end{array}$ & $\begin{array}{l}\text { - BlaBlaCar Italy } \\
\text { (https://www.youtube.com/user/BlaBlaCarlt } \\
\text { aly) } \\
\text { - } \text { Frédéric Mazzella, CEO, BlaBlaCar - Startup } \\
\text { Europe } \\
\text { (https://www.youtube.com/watch?v=gZdN7 } \\
\text { baQjO8) } \\
\text { - } \text { Nicolas Brusson \& Frederic Mazzella - } \\
\text { BlaBlaCar - LeWeb London } 2013 \\
\text { (https://www.youtube.com/watch?v=7PH0o } \\
\text { gmZWTw) } \\
\text { - Nicolas Brusson, BlaBlaCar - NOAH15 London } \\
\text { (https://www.youtube.com/watch?v=peV_- } \\
\text { 7TQMtw) } \\
\text { - Are you Bla, BlaBla, or BlaBlaBla } \\
\text { (https://www.blablacar.com/newsroom/pre } \\
\text { ss-releases?page=2\&page=3\&page=4) }\end{array}$ \\
\hline $\begin{array}{l}\text { Press releases and } \\
\text { Magazine articles }\end{array}$ & 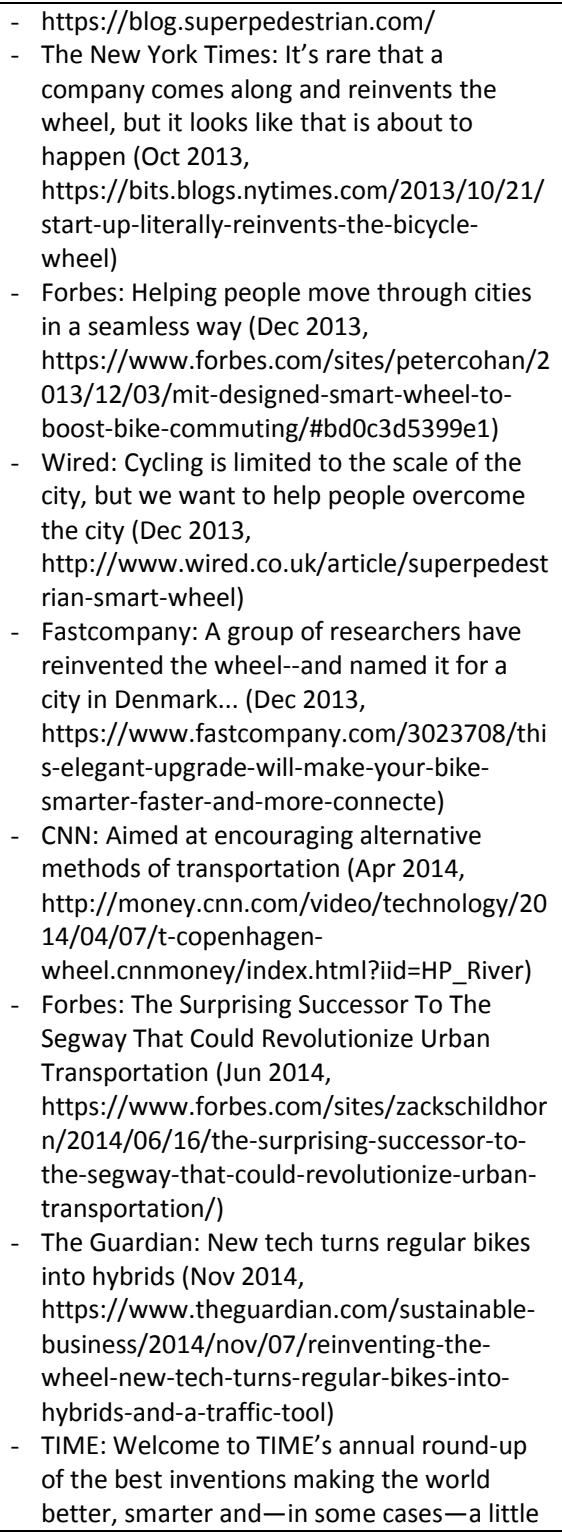 & 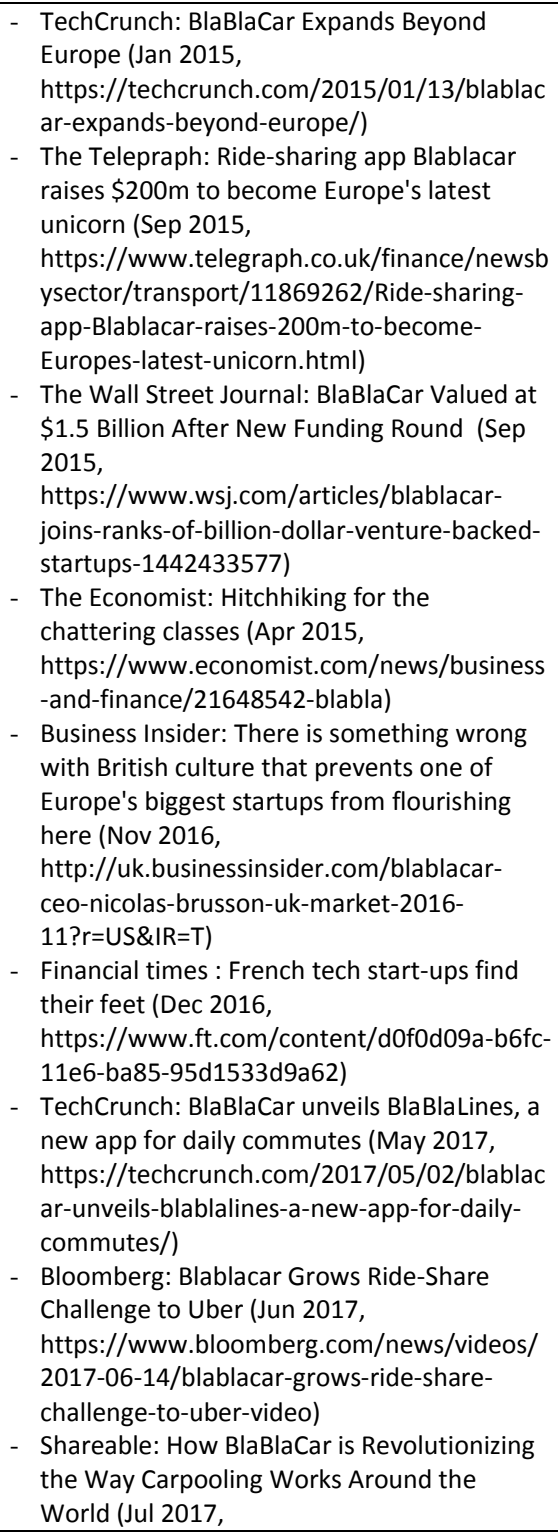 \\
\hline
\end{tabular}


more fun (Nov 2014

http://time.com/3594971/the-25-bestinventions-of-2014/item/the-wheel-thatgives-bikers-a-boost/)

- BBC: The Copenhagen Wheel can be attached to most bicycles and contains an onboard computer, battery, sensors and motor which respond to the rider's pedalling behaviour (Feb 2015,

https://www.bbc.co.uk/programmes/p02ky h74)

- The New York Times: ... it feels like flying (Jun 2015,

https://www.nytimes.com/2015/06/21/opin ion/sunday/dagur-eggertsson.html?_r=1)

- Forbes: Simply put, the Wheel is fun and, in the way of the best of technologies, so seamless that you forget it's there (Apr 2017,

https://www.forbes.com/sites/anthonykarcz /2017/04/11/superpedestrian-hexagon-biketech/\#3d6d42c32ec1) ttps://www.shareable.net/blog/how-

blablacar-is-revolutionizing-the-way-

carpooling-works-around-the-world)

\section{Table 1. Data Collection}




\section{APPENDIX 2 - COPENHAGEN WHEEL: OBJECTIVES, TECHNOLOGIES, MEANINGS, AND RESULTS}

\begin{tabular}{|l|l|}
\hline \multicolumn{1}{|c|}{$\begin{array}{c}\text { Copenhagen Wheel } \\
\text { Copenhagen (DK), 2010 }\end{array}$} \\
OBJECTIVES \\
$\begin{array}{l}\text { Reduce energy consumption and air pollution as a component of a platform for } \\
\text { individual behavioural change. } \\
\text { Gather real-time data on the urban environment. }\end{array}$
\end{tabular}

\section{TECHNOLOGIES}

The wheel uses a technology similar to KERS (Kinetic Energy Recovery System) using Formula-One-inspired technology. When the unit brakes, kinetic energy is recuperated by an electric motor and stored by batteries within the wheel so that the energy can be used later or when needed.

Smart lock: If somebody tries to steal the unit, it goes into a mode in which the brake regenerates the maximum amount of power and sends you a text message. Therefore, in the worst-case scenario, the thief will have charged the batteries before the bike is returned.

\section{MEANINGS}

The Copenhagen Wheel quickly and easily turns the bike you already own into an electric bike with regeneration and realtime environmental sensing capabilities.

This device can change your experience of riding and your experience of the city.

"Over the past few years, we have seen a type of 'biking renaissance,' which started in Copenhagen and is now transforming the urban experience in many cities from Paris to Barcelona or Montreal," says Carlo Ratti, Director of the MIT SENSEable City Lab. "We could also call it a 'Biking 2.0' revolution, whereby cheap electronics allow us to augment bikes and convert them into a more flexible, on-demand system. For us, this project is a component of the answer to the question of how to make using a bike even more attractive".

Smart, responsive and elegant, the Copenhagen Wheel is a new emblem for urban mobility. Controlled through a smart phone, the Copenhagen Wheel becomes a natural extension of everyday life. The phone can be used to unlock and lock the bike, change gears, and select the amount of motor assist. As the rider cycles, the wheel's sensing unit also captures the effort level and information on the surroundings, including road conditions, carbon monoxide levels, noise, ambient temperature, and relative humidity. The user can access these data through the phone or the web and use it to plan healthier bike routes to achieve exercise goals or to meet up with friends on-the-go.

This design turns virtually any bicycle into a vehicle resembling a hybrid car.

\section{RESULTS}

This project has received several awards as well as institutional and international recognition. CPHWhell is licensed to Superpedestrian in Cambridge and pre-sales started in December 2013. 
APPENDIX 3 - COPENHAGEN WHEEL: TECHNOLOGY AND CULTURAL PRODUCTION NETWORK

\begin{tabular}{|c|c|c|c|c|}
\hline \multirow{5}{*}{$\begin{array}{l}\text { Technology } \\
\text { Network }\end{array}$} & Name & Profile & Competences & Contribution \\
\hline & Eric Baczuk & $\begin{array}{l}\text { - GE Research Fellow at MIT SENSEable City Lab } \\
\text { - Climate Engineering Assistant at Transsolar } \\
\text { Energietechnik GmbH } \\
\text { - Intern Architect at Foster + Partners }\end{array}$ & Renewable Energies and Environment & $\begin{array}{l}\text { Project Leader (coordinator and planner rather } \\
\text { than visionary) }\end{array}$ \\
\hline & $\begin{array}{l}\text { Giovanni Alli, Engineer } \\
\text { Leigh Christie, Engineer (SENSEable } \\
\text { City Lab) } \\
\text { Otto Ng, Architect } \\
\text { Pierfrancesco Spagnol, Engineer } \\
\text { James Simard, GIS Analyst } \\
\end{array}$ & Multidisciplinary based on technology & $\begin{array}{l}\text { Various technological fields: } \\
\text { - Renewable energies and environment } \\
\text { - Software engineering } \\
\text { - Computational design }\end{array}$ & $\begin{array}{l}\text { Core team - Project developers } \\
\text { Knowledge of their personal technological } \\
\text { expertise throughout the entire project }\end{array}$ \\
\hline & Ducati Energia s.p.a. & $\begin{array}{l}\text { - Italian company that designs and manufactures } \\
\text { motorcycles }\end{array}$ & $\begin{array}{l}\text { Ducati is best known for high performance } \\
\text { motorcycles characterized by large capacity } \\
\text { four-stroke and } 90^{\circ} \mathrm{V} \text {-twin engines }\end{array}$ & $\begin{array}{l}\text { Technical and manufacturing support } \\
\text { throughout the entire project development }\end{array}$ \\
\hline & $\begin{array}{l}\text { Michael Lin (from Smart Cities Group } \\
\text { at MIT) }\end{array}$ & $\begin{array}{l}\text { - Proficient in statistical machine learning methods } \\
\text { and their application to large-scale data analysis in } \\
\text { computational biology. } \\
\text { - Background in computer science and software } \\
\text { engineering. }\end{array}$ & $\begin{array}{l}\text { Software engineering: computational } \\
\text { genomics, machine learning, functional } \\
\text { programming }\end{array}$ & Initial prototype of the wheel (technical work) \\
\hline \multirow{4}{*}{$\begin{array}{l}\text { Cultural } \\
\text { Production } \\
\text { Network }\end{array}$} & Name & Profile & Competences & Contribution \\
\hline & Carlo Ratti & $\begin{array}{l}\text { - Associate Professor of the Practice of Urban } \\
\text { Technologies, and Director, SENSEable City Lab, MIT } \\
\text { - Director, MIT Italy Program, International Science } \\
\text { and Technology Initiatives } \\
\text { - Partner, Carloratti Associati - Walter Nicolino \& } \\
\text { Carlo Ratti, architecture design office } \\
\text { - Real-time city research initiative within the MIT } \\
\text { SENSEable City Lab } \\
\text { - Graduated in Industrial Design at the Politecnico di } \\
\text { Milano } \\
\text { - PhD in Design Sciences }\end{array}$ & $\begin{array}{l}\text { Technology application (e.g., digital and } \\
\text { sensor monitoring) in future urban landscape } \\
\text { development }\end{array}$ & SENSEable City Lab director \\
\hline & Christine Outram & $\begin{array}{l}\text { - Partner at Re:Imagine Group } \\
\text { - Founder and director of City Innovation Group, a } \\
\text { global think tank of researchers and entrepreneurs } \\
\text { - Masters of Architectural Studies in Architecture \& } \\
\text { Urbanism, special focus in distributed technologies } \\
\text { and cities, MIT }\end{array}$ & $\begin{array}{l}\text { Creative strategy and design, community } \\
\text { mobilization and initiatives that utilize 'big } \\
\text { data' to create smarter, more sustainable } \\
\text { cities and new business eco-systems }\end{array}$ & $\begin{array}{l}\text { Project Leader - First Phase. Mainstay of } \\
\text { instilling the innovative culture and include the } \\
\text { user experience as a core element in the project } \\
\text { brief }\end{array}$ \\
\hline & Max Tomasinelli, Photographer & & & Help bring the image of the wheel to the world \\
\hline
\end{tabular}


APPendix 4 - BlaBlaCAR: OBJeCtives, teChNOLOgIeS, MEANINGS, AND RESULTS

\begin{tabular}{|l}
\hline OBJECTIVES \\
Create a new transport network built on people that could bring efficiency to road \\
transportation, solve congestion problems, and make travel affordable and social.
\end{tabular}

\section{TECHNOLOGIES}

Architecture:

- $\quad$ Online site with dedicated customer service, state of the art web features

- $\quad$ Mobile applications both for Android and iOS were introduced in 2007

Thus, the platform as a whole is built on existing features and tools, and exploits the internet's great potential as a means of growth and communication.

\section{MEANINGS}

BlaBlaCar connects drivers who have empty seats with passengers looking for a ride. Most journeys are long distance (over $150 \mathrm{~km}$ ) and this contributes to increasing the efficiency of road transport and reducing the environmental impact. With regard to the message they share, people are the core element. More precisely, it is not about people themselves but about the relations among individuals, thus the social side is mostly empowered.

Even the name of the platform represents this social aspect. They called it BlaBlaCar because when new members create their profiles they are asked to indicate their level of in-car chattiness from "Bla", "BlaBla", to "BlaBlaBla".

In sum, the platform proposes a new concept of travel understood as affordable and social.

\section{RESULTS}

Since its creation in 2006, it has grown at a reasonably high speed and is now the largest European social ride-sharing network. It has 35 million members in 22 countries of which around 4 million travel every month. Furthermore, an estimated $1,000,000$ tons of $\mathrm{CO}_{2}$ and 500,000 tons of fuel were saved last year. 
APPENDIX 5 - BLABLACAR: TECHNOLOGY AND CULTURAL PRODUCTION NETWORK

\begin{tabular}{|c|c|c|c|c|}
\hline \multirow[b]{3}{*}{$\begin{array}{l}\text { Technology } \\
\text { Network }\end{array}$} & Name & Profile & Competences & Contribution \\
\hline & Francis Nappez & $\begin{array}{l}\text { - Co-Founder of BlaBlaCar } \\
\text { - Prior job: technical developer at Free } \\
\text { Illiad, Orange and Meetic } \\
\text { - Services et réseaux de communication } \\
\text { from Université Joseph Fourier }\end{array}$ & - Mobile infrastructure & $\begin{array}{l}\text { - Leads the technical evolution of the platform } \\
\text { - Knew how the BlaBlaCar product would } \\
\text { actually work from idea to implementation }\end{array}$ \\
\hline & Nicols Brusson & $\begin{array}{l}\text { - Co-Founder of BlaBlaCar } \\
\text { - Prior job: start-ups in Silicon Valley and } \\
\text { VC in London } \\
\text { - MBA from INSEAD } \\
\text { - Masters of Science in Optics from the } \\
\text { Ecole Superieure d'Optique } \\
\text { - Master of Science I Applied Physics from } \\
\text { Paris XI University } \\
\text { Computer Science from Stanford }\end{array}$ & $\begin{array}{l}\text { - Transport industry disruption } \\
\text { - Scaling up of innovative businesses }\end{array}$ & - Leads the company's international growth \\
\hline & \multicolumn{2}{|r|}{ Profile } & Competences & Contribution \\
\hline $\begin{array}{l}\text { Cultural } \\
\text { Production } \\
\text { Network }\end{array}$ & Fréréric Mazzella & $\begin{array}{l}\text { - CEO \& Founder of BlaBlaCar } \\
\text { - Former NASA researcher } \\
\text { - MBA from INSEAD } \\
\text { - Masters of Science in Computer Science } \\
\text { from Stanford } \\
\text { - Masters of Physics from ENS UIm }\end{array}$ & $\begin{array}{l}\text { - Entrepreneurship } \\
\text { - Sustainability } \\
\text { - Internet Strategy }\end{array}$ & $\begin{array}{l}\text { - The idea of BlaBlaCar came from his own } \\
\text { search for a travel solution to visit his family } \\
\text { - Drives the company's vision. }\end{array}$ \\
\hline
\end{tabular}

